\title{
PSYCHE
}

VOL. XXXVI

MARCH, 1929

No. 1

\section{THE IDENTITY OF THE ANT GENERA GESOMYRMEX MAYR AND DIMORPHOMYRMEX ERNEST ANDRE. ${ }^{1}$}

\section{By William Morton Wheeler}

During the examination of a considerable number of ants collected by Dr. L. G. K. Kalshoven in the teak-forests of Java, I have come upon an undescribed species of Gesomyrmex, represented by a graded series of workers, all taken from a single colony and demonstrating that the singular Formicine genera Gesomyrmex and Dimorphomyrmex are synonymous. I have long surmised this identity, because there are no significant differences among the worker phases, except in the proportions of the head, eyes, clypeus, frontal carinæ and mandibles. Even the antennæ are the same and consist of only 8 joints in the worker, instead of 12 , which is the number observed in the great majority of Formicidæ. But hitherto so few specimens of the two genera have been seen and the sexual forms have been so imperfectly known that no definite statements could be made in regard to their affinities.

Gesomyrmex was established sixty years ago (1868) by Mayr for a peculiar, large-eyed ant, $G$. hoernesi, which he found in the Baltic amber, of Lower Oligocene Age. In 1892 Ernest André described two extant species of ants taken by Chaper in the Kapoewas Basin, North Borneo. One of them, which he called $G$. chaperi, was evidently very closely related to the amber form; for the other, which was larger and had a much larger and more rectangular head and smaller eyes, he erected a new genus, Dimorphomyrmex. This form, Dimorphomyrmex janeti, he described as possessing dimorphic

1Contributions from the Entomological Laboratory of the Bussey Institution, Harvard University No. 308. 
workers, with heads of similar structure but of different sizes. Then Emery, in 1906, discovered in the Baltic amber a form which closely resembled the Bornean janeti and described it as $D$. theryi. While reviewing the ants of the Baltic amber in 1913 I was able to recognize several specimens of $G$. hoernesi and $D$. theryi and two intermediate forms which I described as $G$. annectens and $D$. mayri. Two years later (1916) I described a winged female from the Island of Luzon, in the Philippines as Dimorphomyrmex luzonensis, and in 1921 another species, Gesomyrmex howardi, from a couple of workers taken by Prof. C. W. Howard near Canton, China. These workers I interpreted as major and minor workers respectively and noted that the former resembled the worker of Dimorphomyrmex. The new species from Java now shows that the specimens of howardi are really media and minima workers, that those of $G$. hoernesi and chaperi, described by Mayr and André are minimæ, that those of $D$. janeti are maximæ and mediæ of $G$. chaperi, and that the workers of D. theryi, D. mayri and G. annectens are in all probability the maximæ, large mediæ and small mediæ respectively of $G$. hoernesi. This will be clear from the following description and figures of the new species brought to light by Dr. Kalshoven.

Gesomyrmex kalshoveni sp. nov.

Worker maxima. (Fig. 1, a-d) Length 5-6.6 mm.

Head subrectangular, about $11 / 4$ times as long as broad, slightly narrower in front than behind, with the sides distinctly concave in front of the middle; the posterior border feebly concave, the posterior corners convex and rounded; the dorsal and gular surfaces rather flat. Eyes elongate, convex, scarcely reniform, with straight or very nearly straight internal and impressed posterior orbits, one-third as long as the head and well up on its dorsal surface. Ocelli minute, unpigmented, the anterior smaller than the two posterior, which are on a level with the posterior orbits of the eyes. Mandibles stout, convex, with strongly rounded external borders, 8-toothed, the first, second, fourth, sixth and eighth tooth, counting from the apex, larger than the others and rather blunt. Clypeus short and flat, its anterior 

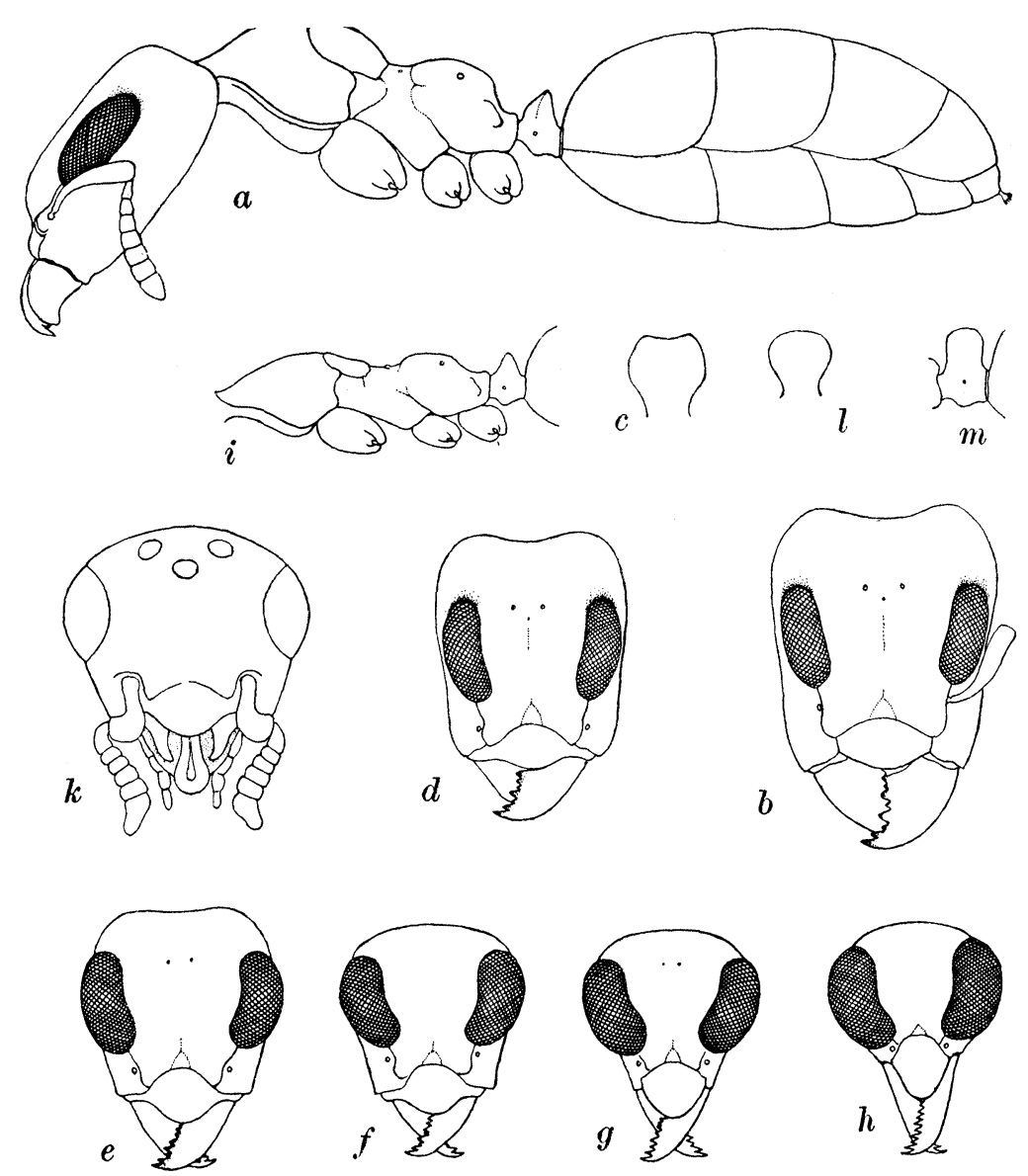

Fig. 1. a. Gesomyrmex kalshoveni sp. nov. Maxima worker in profile; $b$. head of same; $c$. petiole from front; $d$. head of small maxima; $e$. head of large media; $f$. of small media; $g$. of large minima; $h$. of small minima; $i$. thorax and petiole of same; $k$. head of male semipupa; $l$. petiole of $G$. howardi Wheeler from front; $m$. same in profile. 
border slightly and evenly rounded, scarcely projecting in the middle; its lateral portions not reaching the anterior corners of the head, convex but not auriculate. Frontal area distinct, moderately large and triangular; only a portion of the frontal groove developed in the middle of the head just anterior to the ocelli; frontal carinæ widely separated, subparallel, rather erect and slightly lobular anteriorly, continued back to the anterior orbits of the eyes. Antennæ 8-jointed; scapes curved basally, gradually thickened distally, their tips reaching somewhat beyond the middle of the eyes; funiculi distinctly enlarged apically, first joint twice as long as broad; second and third $11 / 2$ times as long as broad, remaining joints nearly as broad as long, except the terminal joint which is somewhat longer. Thorax stout anteriorly, the pro- and mesonotum convex, forming together a hemispherical mass, separated by a distinctly impressed suture, rounded above in profile, the former as broad as long with a faint median longitudinal impression behind; the latter as long as broad, subcircular with straight posterior and rather deeply impressed anterior and lateral sutures. Behind the mesonotum the thorax is divided into two regions by a transverse dorsal furrow; the shorter anterior portion, representing the metanotum is depressed and bears the somewhat projecting metanotal spiracles at its sides; the posterior portion, representing the epinotum, is as broad as long, with the base somewhat convex and bearing the epinotal spiracles at the middle of its sides. Posteriorly it passes into the distinctly shorter, sloping declivity, with which it forms a distinct, obtuse angle. Petiole small; its node from above transversely elliptical, nearly $12 / 3$ times as broad as long; in profile distinctly cuneate, with convex anterior and posterior surfaces, the moderately sharp superior border transverse, feebly and broadly excised or sinuate in the middle. Gaster large, elongate-elliptical. Legs stout; all the femora somewhat thickened; spurs of middle and hind tibiæ very short; tarsal claws large and stout.

Smooth and shining; mandibles coarsely punctate, with a. few incomplete longitudinal rugules; head more finely punctate; median portion of clypeus, front and cheeks finely and longitudinally striate as far back as the eyes. 
Thorax, petiole, gaster and appendages very minutely and sparsely punctate, the gaster also very delicately and indistinctly, transversely coriaceous.

Hairs yellowish white, absent on the body, except at the tip of the gaster and on the mandibles, clypeus and front. On these latter regions they are numerous, short, erect, stubby and obtuse. Scapes with short oblique hairs. Pubescence undeveloped, except on the tibiæ where it is very short, dilute and appressed.

Honey yellow; gaster and legs paler and more whitish yellow, the several gastric segments very faintly infuscated posteriorly; frontal carinæ and mandibles red, the latter with black teeth and dental border; impressions of the posterior orbits dark brown; claws and tarsal articulations reddish.

Worker media. (Fig. 1 e and f) Length 3.5-4.5 mm.

Differing from the maxima mainly in the characters of the head, which is proportionately smaller and only $11 / 6$ to $11 / 5$ times as long as broad; its posterior portion shorter and more rounded, its anterior portion more narrowed, with proportionally larger eyes, which are more convex, and reniform, i.e. with concave internal orbits and one half as long as the sides of the head. Posterior ocelli represented by minute pits in the larger, usually absent in the smaller specimens. Mandibles 7-8 toothed and more elongate and less convex than in the maxima, with less convex external borders and only the first, fourth and fifth tooth enlarged and more acute, the third, seventh and eighth very minute. Median portion of the clypeus longer, more convex posteriorly, its anterior portion more advanced and lobular, depressed. All the funicular joints longer than broad, except the penultimate. Thorax somewhat more slender than in the maxima, pronotum without longitudinal impression; mesonotum longer than broad, with more nearly parallel sides; its surface flattened and even slightly concave in profile. Petiole as in the maxima, but slightly more narrowed above.

In the larger media there are distinct striæ and short stubby hairs on the front, though the latter are less numerous; in the small media these hairs are absent and the striæ are very indistinct or obsolete. Color like that of the 
maxima, except that the mandibles are yellowish, with only the teeth blackish.

Worker minima. (Fig. $1 \mathrm{~g}$-i) Length 2.8-3.2 $\mathrm{mm}$.

Differing from the media in having a still shorter head, in the smallest minima scarcely longer than broad including the eyes, which are more convex and laterally projecting, decidedly reniform and taking up more than $3 / 4$ of the sides of the head, so that the cheeks and postocular regions are greatly reduced, the latter without distinct corners and with slightly and evenly convex median border. Clypeus much longer and anteriorly projecting, more convex behind and somewhat more concave in front, than in the media. Ocelli represented by a pair of very minute pits or completely absent. Mandibles more elongate, flattened, with straight external borders, the teeth forming a more even crowded series, the apical longer than the basal. Frontal carinæ very short and indistinct. Antennal scapes extending to the posterior third or fourth of the eyes. Thorax more slender, proand mesonotum much less convex, with nearly straight outlines in profile, the latter feebly concave as in the media. Legs slender, but with the femora distinctly enlarged basally.

Mandibles pale yellow with reddish teeth; posterior orbits not tinged with brown. In other respects like the small media. The larger minima is intermediate between the small minima and the small media even in the structure of the mandibular teeth.

Described from 15 workers taken by Dr. L. G. K. Kalshoven in a teak-forest at Semarang, Java. The following are the lengths of the individual (alcoholic) specimens:

Maximæ: $6.6 \mathrm{~mm}$. ; $5: 7 \mathrm{~mm}$.; $5.3 \mathrm{~mm}$.; $5 \mathrm{~mm}$.

Mediæ: 4.5 mm.; 4 mm.; 4 mm.; 4 mm.; 3.8 mm.; 3.8 mm.; 3.5 mm.; 3.5 m.m.

Minimæ: $3.2 \mathrm{~mm}$.; $3 \mathrm{~mm}$.; $2.8 \mathrm{~mm}$.

The variations in structure in all the castes are so finely graduated that there is no hiatus between the smallest specimen measuring $2.8 \mathrm{~mm}$. and the largest measuring $6.6 \mathrm{~mm}$. 
G. kalshoveni must be very close to the form described by André as G. chaperi from the minima and "D. janeti" from the maxima and media worker. He gives the length of the minima as 3.5 to $4 \mathrm{~mm}$., of the media as $3.5 \mathrm{~mm}$. and the soldier as $6 \mathrm{~mm}$. If his descriptions were drawn from cabinet specimens the fact that the largest minima was longer than the media may be explained on the supposition that the gasters of the two specimens had contracted unequally on drying. Such differences are, of course, frequent also in the gasters of living or alcoholic specimens of the same caste, owing to variable distension of the crop. The maxima of kalshoveni differs from that of chaperi in lacking the lateral auriculate expansions of the clypeus, in possessing longer funicular joints and nonpigmented ocelli, a decidedly more convex pronotum and in having the stubby hairs on the front and clypeus simple and truncate instead of bifid or multifid at their tips. André describes these hairs as "appearing as if surmounted or even crowned with minute spines." Emery has cited G. chaperi (as D. janeti) from Sumatra, but it is not improbable that his specimens belonged to the Javan rather than to the Bornean species.

The new Gesomyrmex differs from $G$. howardi in the shape of the petiolar node, which in the latter (Fig. 1, l and $\mathrm{m}$ ) is much thicker above, with rounded, entire border, in the epinotum which is shorter in howardi, with much less convex base and with the base and declivity subequal. The sculpture of howardi is decidedly coarser, especially on the epinotum and pleuræ, so that the surface is more opaque. The color is also darker and more brownish or sordid than in kalshoveni and chaperi. There are distinct striæ on the front in the media and minima of howardi. It is, of course, not improbable that all four living species of Gesomyrmex, including $G$. luzonensis, which is known only from the female, may prove to be merely so many local races (sub-species or varieties), when sufficient material of these forms has found its way into our collections.

It would be interesting to revise the fossil species of Gesomyrmex in the light of the preceding discussion. Of the material which I studied in 1913 and soon afterward returned to the Königsberg museums, I retained only a single block of amber containing a large and a small worker of " $D$. 
theryi" side by side and designated as K. 6397, in my paper on the "Ants of the Baltic Amber" (1914). The large worker, which measures fully $7.5 \mathrm{~mm}$., is very clear, but the head of the small worker, which measures only $4 \mathrm{~mm}$., is obscured by a film and some bubbles of air. I have now had the block cut down and repolished, so that the head of the small individual is more clearly visible. It proves to belong to the form which I called $D$. mayri, and is really a media of the same species as the large (maxima) worker. The latter has small but very distinct ocelli, but none can be detected in the companion specimen. Since G. annectens is clearly intermediate between D. mayri and G. hoernesi, the former is, in all probability the large minima, whereas the latter represents the small minima of Mayr's species. I am, therefore, of the opinion that all the specimens of Dimorphomyrmex and Gesomyrmex in the Baltic amber belong to a single polymorphic species, which should be known as $G$. hoernesi Mayr. ${ }^{1}$ This is of considerable interest, because it shows that as far back as the Lower Oligocene one Formicine ant had not only reached a high degree of specialization in the reduction of the number of antennal joints of the worker from 12 to 8, but that this caste had become as polymorphic as it is in the living species of the genus now confined to Indonesia and Southern China. And conversely, the very rare and sporadic occurrence of these forms shows that they are really living fossils which have undergone no significant modification since the Early Tertiary.

The workers collected by Dr. Kalshoven were accompanied by several milk-white larvæ of different sizes and a single semipupa. The larvæ resemble those of other Formicinæ in shape, but are almost hairless. The head is very small and subglobular, the mandibles minute, with only an apical tooth, which is drawn out into a slender, acute point. The semipupa measures a little over $7 \mathrm{~mm}$. and is not enclosed in a cocoon. We must infer, therefore, that the pupæ of Gesomyrmex are naked as in a few other genera of Formicinæ. (Ecophylla, Prenolepis, Paratrechina). The semipupa is clearly a male. It has well-developed wing-pads and rudiments of the genital valves, and the imaginal head (Fig. 1, k)

1Compare my figures 50-53 in "The Ants of the Baltic Amber." 
is sufficiently developed to enable me to determine its main peculiarities. As will be seen from the figure, it is broader than long, with evenly rounded, convex, postocular region; the eyes are very small, for a male, not longer than the cheeks, not very convex and situated at the sides of the head; the ocelli are moderately large but flat; the antennal insertions are very far apart and near the anterior orbits; the antennal scapes are short and abruptly bent outwards at their tips (probably a pupal character), the funiculi short, thick and distinctly 6-jointed (!), instead of 7-jointed as in the worker; the clypeus is rounded and slightly projecting in the middle; the mandibles small, narrow, edentate and rather blunt. The specimen is of considerable interest because no other male of the genus is known, though Mayr carefully described and figured what he took to be the male of $G$. hoernesi from a rather poorly preserved specimen in the Baltic amber. Although we must allow in my description of the male semipupa of G. kalshoveni for later pupal changes (especially, perhaps, in the number of funicular joints), it is clear, nevertheless, that the male of this species is decidedly different from Mayr's specimen. This has enormous eyes, constituting the greater portion of the head, very minute pointed mandibles, very slender 11-jointed antennæ and very minute genital appendages. Although the wingvenation agrees closely with that of the female G. luzonensis, I believe that Mayr's specimen must belong to some other hitherto unidentified Formicine genus.

Two other fossil ants supposed to be allied to Gesomyrmex may be briefly considered in this connection. The first of these is a large-eyed worker which Emery described from the Sicilian amber of Miocene age, as Gesomyrmex corniger. His description and figures, however, show that this insect cannot be included in the genus Gesomyrmex. The shape of its head, mandibles and petiole, the presence of long oblique spines on the epinotum, the very long maxillary palpi, the abundant pilosity, peculiar rugosity of the head, pro-and mesonotum, the blackish coloration and the possibility that its antennæ may be really 9 or 10 instead of 8-jointed, led me to place it in a distinct genus, Sicelomyrmex. Apart from the peculiar recurved horns at its posterior corners, the head of this ant is more suggestive of the Neotropical 
Gigantiops and the Congolese Santschiella than of Gesomyrmex. The other ant is Prodimorphomyrmex primigenius which I described from the Baltic amber. It approaches Gesomyrmex much more closely, but has smaller eyes, 10jointed antennæ and a shorter thorax. Only a single imperfect specimen was observed.

The following would now be the corrected synonymy of the known species of the genera I have been considering:

\section{Living Species}

Gesomyrmex chaperi Ern. André. Borneo, Sumatra.

Gesomyrmex chaperi Ern. André, Mém. Soc. Zool. France 5, 1892 p. 47, Figs. 1-3, worker minima; Emery, Gen. Insect. Formicinæ 1925, p. 47, Pl. 2 Fig. 3, worker media.

Dimorphomyrmex janeti Ern. André, Mém. Soc. Zool. France 5, p. 51 Figs. 4 and 5; worker maxima and media.; Emery, Ann. Soc. Ent. Belg. 43, 1894, p. 494, worker maxima.; Emery, Gen. Insect. Formicinæ 1925, p. 47, worker maxima and media.

Gesomyrmex luzonensis (Wheeler). Philippines.

Dimorphomyrmex luzonensis Wheeler, Proc. New England Zool. Club. 6, 1916 p. 16, Fig. 4, female; Emery, Gen. Insect. Formicinæ 1925, p. 47, female.

Gesomyrmex howardi Wheeler. China.

Gesomyrmex howardi Wheeler, Psyche 28, 1921 Fig. 2, worker media and minima; Emery, Gen. Insect. Formicinæ 1925 , p. 47, worker media and minima.

Gesomyrmex kalshoveni Wheeler. Java.

Described above p. 2 from the maxima, media and minima worker and male semipupa. 


\section{Extinct Species.}

Gesomyrmex hoernesi Mayr. Baltic Amber.

Gesomyrmex hoernesi Mayr, Beitr. Naturk. Preuss. 1, 1868 p. 52, Fig. 38 to 41, worker minima; not the male; Dalla Torre, Catalog. Hymen. 7, 1893 p. 176 ; Ern. André, Bull. Soc. Zool. France 20, 1895 p. 82 ; Handlirsch, Foss. Insekt. 1908 p. 859; Wheeler, Ants, etc. 1910 p. 170, Fig. 100; Wheeler, Schrift. physikal-ökonom. Gesell. Königsberg 55, 1914, p. 108, Fig. 53, worker minima.

Dimorphomyrmex theryi Emery, Bull. Soc. Ent. France 1905 p. 188 Fig. 1, worker maxima; Handlirsch Foss. Insekt. 1908 p. 868, worker maxima; Wheeler, Ants, etc. 1910 p. 173, Fig. 98, worker maxima; Wheeler, Psyche 17, 1910 p. 132; Wheeler, Schrift. physical-ökonom. Gesell. Königsberg 55, 1914, p. 104, Fig. 50, worker maxima.

Dimorphomyrmex mayri Wheeler, ibid. p. 106, Fig. 51, worker media (large).

Gesomyrmex annectens Wheeler, ibid. p. 107, Fig. 52, worker media (small).

Prodimorphomyrmex primigenius Wheeler. Baltic amber.

Prodimorphomyrmex primigenius Wheeler, Schrift. physikalökonom. Gesell. Königsberg 55, 1914, p. 112, Fig. 54, worker.

Sicelomyrmex corniger (Emery) Sicilian amber.

Gesomyrmex corniger Emery, Mem. Ist. Bologna (5) 1, 1891, p. 581, Figs. 33-35, worker; Wheeler, Ants, etc. 1910, Fig. 101, worker.

Sicelomyrmex corniger Wheeler, Schrift. physikal-ökonom. Gesell. Königsberg 55, 1914, p. 111, worker; Wheeler, The Social Insects, etc., 1928, Fig. 27, worker.

The affinities of Gesomyrmex and Dimorphomyrmex to other Formicine genera have been discussed by Forel and Emery. In his revision of the subfamily Formicinæ (1925), 
Emery places the two genera in his sixth tribe, or first tribe of the section Euformicinæ, which he bases on characters drawn from the gizzard (proventriculus). Unfortunately, he named this tribe Dimorphomyrmicini (his Dimorphomyrmii of 1895). Since the genus Dimorphomyrmex now passes into the synonymy, the tribe will have to be called Gesomyrmicini (Ashmead, 1905). This tribe, according to Emery, would contain besides Gesomyrmex only the genera Brachymyrmex, Aphomomyrmex and Cladomyrma. The three latter are supposed to be so closely interrelated that they form together the subtribe Brachymyrmicini, leaving Gesomyrmex to represent a subtribe by itself, to which Emery gave the same name as the tribe (Dimorphomyrmicini). He evidently based his tribe on the small number of antennal joints (8-9 in the worker, 8-10 in the female) instead of the 12 observed in both of these castes in all Euformicine genera, except certain fossils (Dryomyrmex and Prodimorphomyrmex). But the general habitus of Gesomyrmex is so different from that of Brachymyrmex, Aphomomyrmex and Cladomyrma, that its relationships would seem to be better expressed by regarding it as the representative of an independent tribe (Gesomyrmicini). This would necessitate raising Emery's subtribe Brachymyrmicini to tribal rank. I believe that the tribe Gesomyrmicini would thus be more naturally placed as one of the series of tribes, including the Santschiellini Forel, Gigantiopini Ashmead and Ecophyllini Ashmead, which are all based on single archaic, relict genera of large-eyed ants. The fossils Prodimorphomyrmex and Dryomyrmex may, perhaps, be assigned to the Brachymyrmicini, but Sicelomyrmex corniger should be regarded as the representative of an extinct tribe, the Sicelomyrmicini.

We are still in the dark in regard to the habits of Gesomyrmex. The well-developed claws in the worker and female and the not infrequent occurrence of $G$. hoernesi in the Baltic amber, suggest that the genus is arboreal. Moreover, the structure and sculpture of the anterior portion of the head in the maxima and female and the peculiar stubby hairs on the clypeus are reminiscent of some species of Colobopsis and allied subgenera of Camponotus, which live in hollow twigs or small cavities in bark or wood. 

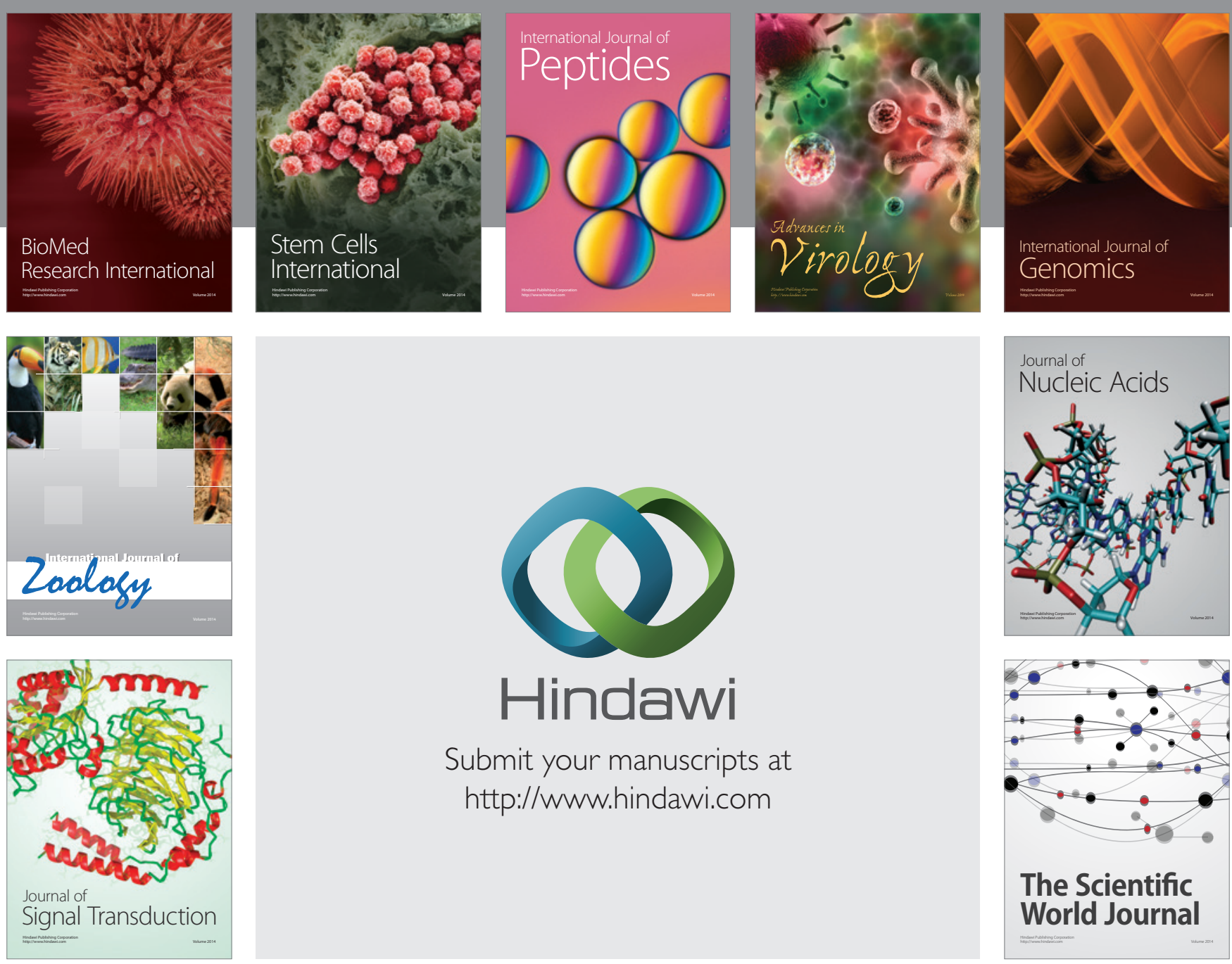

Submit your manuscripts at

http://www.hindawi.com
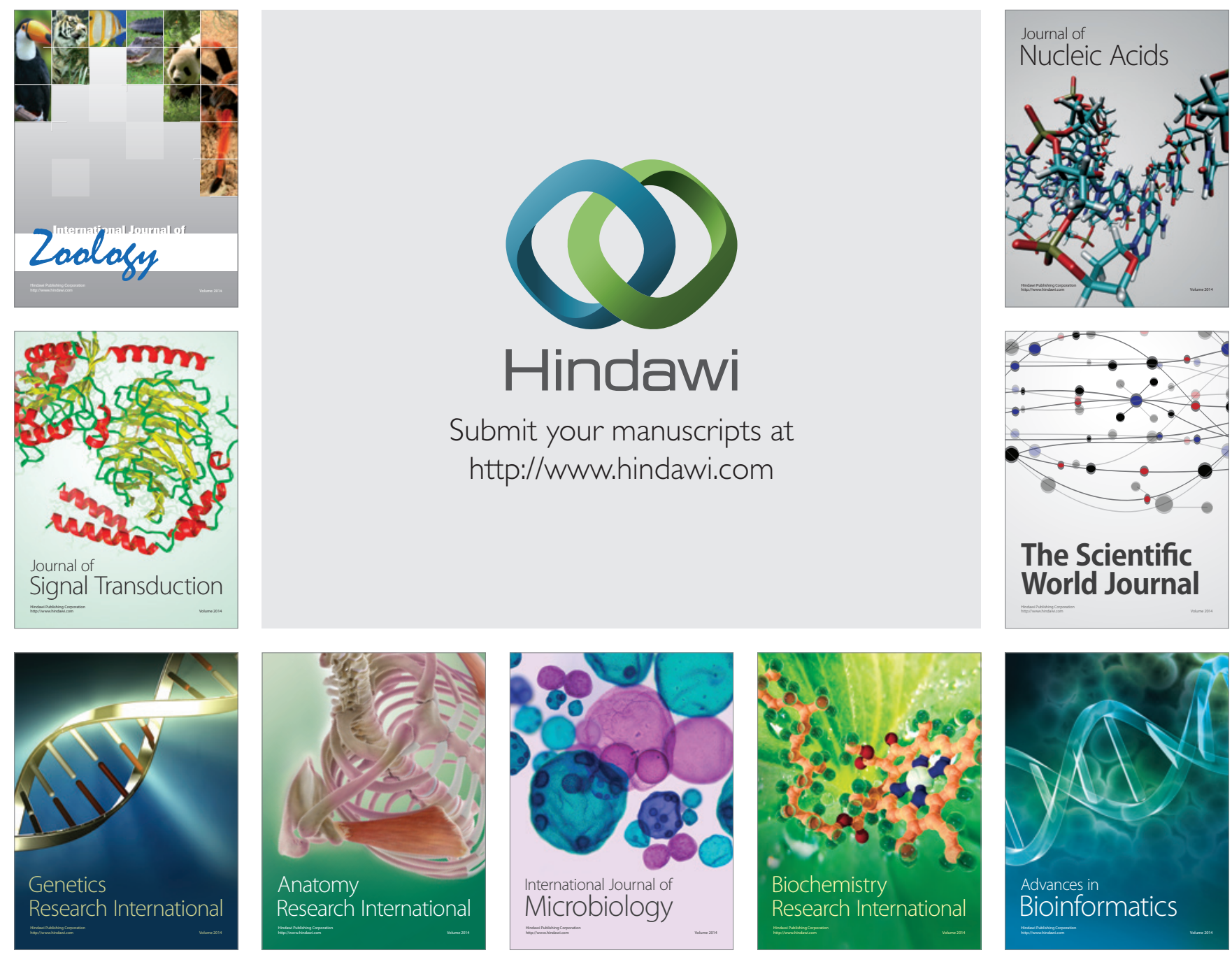

The Scientific World Journal
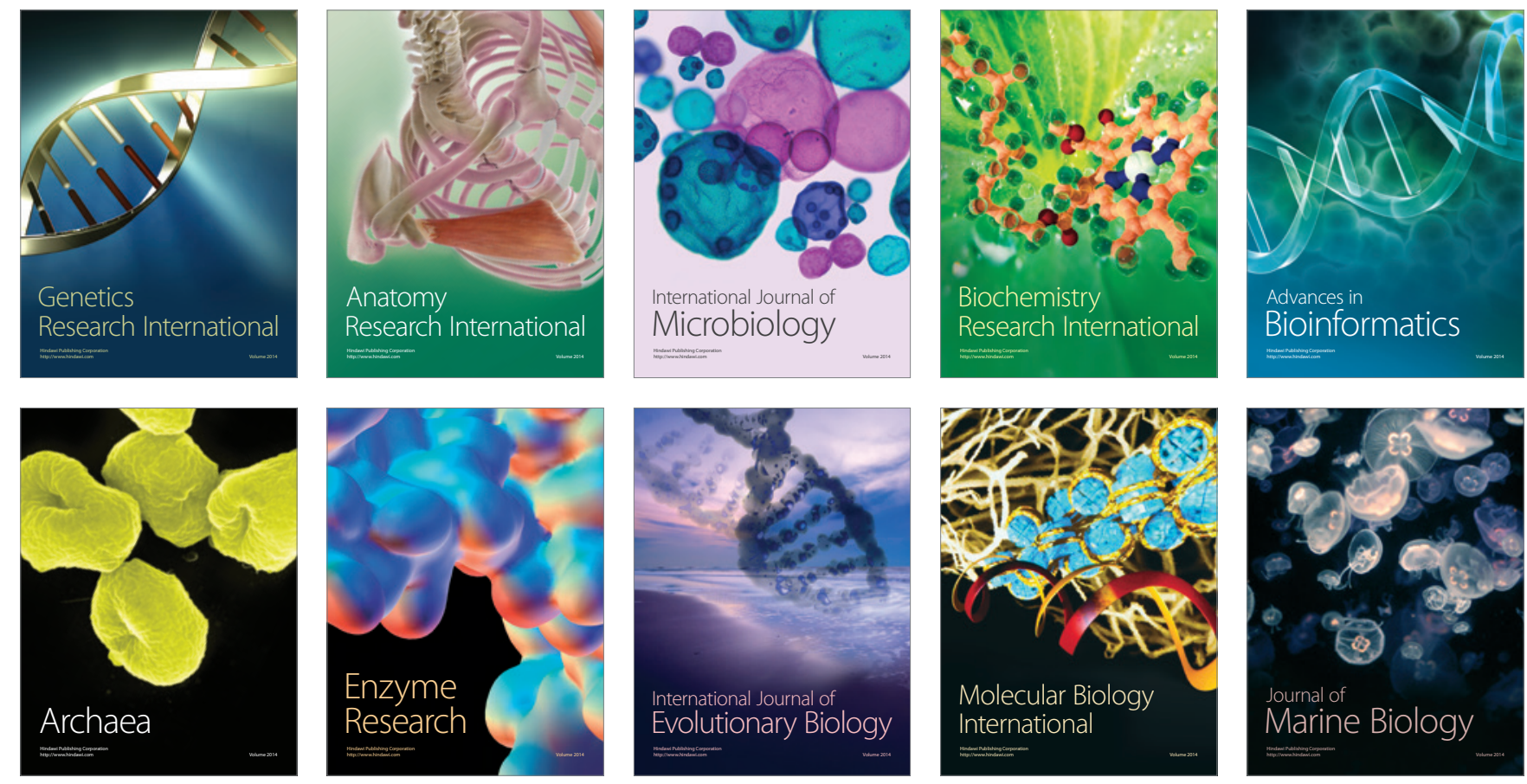